impaired in the premature infant. Preoccupation with maintenance of biochemical homeostasis in the treatment of prematures and renewed interest in tryptophan, tyrosine and phenylalanine metabolism by the newborn prompted us to this study of urinary excretion of tryptophan and tyrosine metabolites by 11 full-term and 12 premature infants on their 1st day of life and 9 full-term and 11 prematures on their 15th day of life. Metabolites from all three main catabolic pathways of tryptophan were detected in both groups of infants. The main differences between full-term and prematures were a) 5-indole-propionic acid was found only in the urine of full-term infants on the first day of life; b) 3indoleacetic acid was not found on the 15th day of life in the urine of full-term infants; and c) on the first day of life the urine of $10-20 \%$ of prematures contained 5-OH-tryptophan, indoxyl-acetyl-glutamine and 5$\mathrm{OH}$-anthralinic acid. On the 15th day of life the number of metabolic products was decreased, probably because tryptophan was now incorporated in proteins.

Twenty phenolic acids were observed in both groups of infants, but their excretion varied a great deal. Homogentisic acid was excreted in the urine of half of the full-term infants on the 15th day of life, but not on the 1st day of life. The appearance of this acid in the urine of some full-term infants on the 15th day of life is suggestive of the maturation of the enzymes functioning in the main metabolic pathway of tyrosine via homogentisic acid.

The 24-hour urinary metacatecholamines and vanilmandelic acid (VMA) were also determined in the same premature and full-term infants. Variations of excretion of VMA generally followed those of metacatecholamines, but the excretion of VMA by the prematures on the 15th day of life was 4-5 fold that of the 1st day. In contrast, a moderately decreased VMA excretion was noted in the urine of full-term infants.

We are inclined to believe that the observed differences in metacholamine and VMA excretion are due to the delayed maturation of 3-O-methyltransferase and monoaminoxidase, the enzymes responsible for the metabolism of catecholamines to VMA. But the marked increase in VMA excretion on the 15th day by the prematures has to be attributed to an 'overmaturation' of the last enzyme or to other factors.
$37 \quad$ Acid-Base and Electrolyte Changes During Exchange Transfusion in the Newborn. Francesca SEverI, G. Belloni and G. Rondrni, Pediatric Clinic of the University of Pavia, Italy.

Twenty-six newborn infants (eighteen full-term infants and eight prematures) requiring exchange transfusion have been included in this investigation. Citrated blood was used. $1 \mathrm{ml}$ of calcium gluconate was added to every $100 \mathrm{ml}$ of blood in 9 full-term infants and in all the prematures; $3 \mathrm{ml}$ of calcium gluconate were added in 9 full-term infants. The exchange transfusion lasted in every case about 2 hours.

The blood samples for plasma $\mathrm{Na}, \mathrm{K}, \mathrm{Ca}$, bilirubin and total protein levels were taken from the umbilical vein before the transfusion, during its course and 1,2 , 3 and 24 hours after the end of the transfusion. At the same time, but also once daily up to the 5 th day, $\mathrm{pH}$, $\mathrm{pCO}_{2}$, base excess and standard bicarbonate were measured with the micromethod of Astrup in the arterialized capillary blood.

The mean values show that in full-term newborns the exchange transfusion caused a continuous rise of the $\mathrm{pH}$ which became more evident after the first half an hour; the highest value was reached $2-3$ hours after the end of the transfusion. The $\mathrm{pH}$ gradually decreased during the following 5 days. The base excess and the standard bicarbonate values, after a slight initial reduction, rose during the transfusion and afterwards, up to the 2nd-24th hour and gradually decreased in the following days. Only slight differences have been observed between the group treated with $1 \mathrm{ml}$ of calcium gluconate to every $100 \mathrm{ml}$ of blood and that treated with $3 \mathrm{ml}$.

In premature infants, a slight initial fall of the $\mathrm{pH}$ values was observed; afterwards the rise of the $\mathrm{pH}$ and the tendency to metabolic alcalosis was slower and less evident than in full-term newborns. Neither in fullterm newborns nor in prematures was observed serious metabolic acidosis caused by exchange transfusion.

$\mathrm{K}$ and total protein plasma levels showed a slight reduction in almost every case during exchange transfusion; bilirubin decreased constantly; Ca plasma levels increased almost in all cases. Na plasma levels showed only slight variations.

\title{
INDEX OF ABSTRACTS
}

(Numbers following entries refer to abstract number)

Aagenaes, O. 3

Acid-base measurement 12

Acid-base metabolism 37

Acidosis 22, 32

- metabolic 5, 12

Adrenogenital syndrome 23

Agathopoulos, A. 36

Albumin test 16

Amino acid transport 29

Amylo-1.6-glucosidase 18

Arginine 29

ARNEIL, G. 21

Aspartate transcarbamylase 20

Atelectasis 32
Autoantibody 35

Badoual, J. 17

Base excess 12

BELAY, M. 10

Belloni, C. 37

Bilirubin 3

- hyperbilirubinemia 4

Blood pressure 9

Blood volume 9

BODA, D. 10

BorRone, C. 26, 33

Boulange, M. 23

BRODEHL, J. 1
Calcium 21

Carbamyl aspartate 20

Celander, O. 9

Ceramide tetrahexoside 26

Ceramide trihexoside 25

Ghemical oxygen demand 10

Chondroitin sulphate B 33

Ghristiansen, P. 34

Colitis, ulcerative 35

Colon 35

Cooke, R. 32

Courtecuisse, V. 19

Curllirer, J. 23

Cuisinier-Gleizes, P. 22 
420

Della Cella, G. 26, 33

Diarrhea 29

- chronic 13

2, 3-Diphosphoglycerate 7

Duarte variant 2

Duchenne dystrophy 24

Duodenum 13

Durand, P. 26, 33

Ebrey, P. 10

EcK, E. 10

E. coli 14

Electroencephalogram 27

ENGEL, K. 12

Erythrocyte 7

Ethanol 18

Evoked potentials 27

- visual 27

Exchange transfusion 9, 37

Fabry syndrome 25

Fat, brown 8

Fatty acids, free 8

FAulkner, S. 24

FRENCK, N. 9

Frits-Hansen, B. 32

Galactose-1-phosphate uridyltransferase 2

Galactosemia 2

GAlOFRE, A. 20

Gastric secretion 34

Gellissen, K. 1

Genetic dependence 6

Grtzelmann, R. 2

Glucose-6-phosphatase 17, 18

Glucose-6-phosphatase dehydrogenase 4

Glycine 28

Glycogenosis 17, 18, 19

Glycolipid 25

Glycolipidosis 26

Granulocytes 30

Granulomatosis 30

Growth 28

- retardation 29

HAGGE, W. 1

Hammarstrom, S. 35

Heart 20

Hemoglobin, fetal 6

Hemolysis 7

Hepatitis, neonatal 3

Hepatomegaly 1

Heterozygote 1

Hitzig, W. 30

Hrbek, A. 27

HuRwitz, R. 20

Hydroxylase 23

Hypercapnia 32

Hypoglycemia 17

Hypoxia 11

- anemic 5

IMMONEN, P. 14

Immunoglobulins 14, 35
Index of Abstracts

- gamma M 14

3-Indoleacetic acid 36

5-Indole-propionic acid 36

Inheritance 24

- sex-linked 30

Inherited disease 2,29, 30

Intrinsic factoŕ 34

Jaundice 3

- neonatal 4

Jejunum 13, 29

Karaklis, A. 4

KeKomakr, M. 29

KJELLMER, I. 11

$\mathrm{KoCH}, \mathrm{A} .28$

Kouvalarnen, K. 14

Krasilnikoff, P. 34

KRETChMER, N. 20

Kutrunen, P. 29

LAGERCRANTZ, R. 35

LAUNIALA, K. 29

LESTRADET, J. 17

LINDBERG, O. 8

Liver 3, 20

LOEB, H. 25

LOWE, C. 28

Lunding, M. 32

Lung 11

Lymphocyte 35

Lysine 29

Malabsorption syndrome 13

Maltase, acid 19

MARUBINI, E. 31

Mathieu, H. 22

Matsaniotis, N. 36

Mental deficiency 24

Metacatecholamine 36

Metcoff, J. 15

Methemoglobinemia 5

Methylene blue 5

Mitochondria 8

Morquio's syndrome 33

Mucopolysaccharide 25, 33

MURANYI, L. 10

Muscular dystrophy 19

- pseudohypertrophic 24

Newborn 7, 9, 27, 37

Nephrotic syndrome 16

Nrcolopoulos, D. 36

Nitrogen balance 28

Noradrenalin 8

Nucleic acids 20

5-OH-Tryptophan 36

Oxygen tension 32

Parathormone 22

Parathyroid 22

PARKKulainen, K. 14

Pentose shunt 30

Peritoneal dialysis 10

Perheentupa, J. 29
Perletti, L. 31

Perlmann, P. 35

Philippart, M. 26

Phosphorylation 8

Pierson, M. 23

Pluss, H. 30

Prematurity 10, 36

PROD'HOM, L. 9

Protein intolerance 29

Protein metabolism 28

Pyrimidines 20

Renal biopsy 16

Renal tubules 21, 29

RenneR, R. 30

Respiratory distress syndrome $10,11,32$

RichaRdSON, F. 24

RoDBro, P. 34

RoNDINI, G. 37

Rosenkranz, A. 16

Rossi, E. 18

ROYER, P. 22

Rylander, E. 8

Salt-losing syndrome 23

Sarcosine

- dehydrogenase 1

- hypersarcosinemia 1

SGHROTER, W. 7

SERENI, F. 31

SEVERI, F. 37

SigdelL, J. 9

Spleenomegaly

Steatorrhea 3

Strontium, radioactive 21

Thermogenesis 8

Tryptophan 36

Twins 6

Tyrosine 28, 36

Umbilical cord 6

Urea 29

Urinary tract infection 14

Valaes, T. 4

Vanilmandelic acid 36

VARGA, F. 5

Vasoconstriction 11

Vasomotor reflexes 9

Vasopressinism 23

VerT, P. 23

Vitamin C 5

Vitamin $\mathrm{K} 3$

Ventilation, artificial 32

VISAKORPI, J. 29

WALKER-SMTTh, J.A. 13

Water, free clearance 23

WeIL, W. 28

WeIPPL, G. 6

WiLson, I. 8

ZUPPINGER, K. 18 